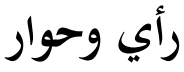

\section{استفتاء علماء الأمة بشأن مواقيت الصلاة وصوم رمضان}

\section{*عبد الحميد أحمد أبو سليمان}

نشرنا من قبل عدداً من المقالات التي تستفتي علماء الأمة في بعض المسائل التي

تيسر على الناس القيام بما هو مطلوب منهم من أحكام الدين وشعائره. وكان الهدف من من من فئن

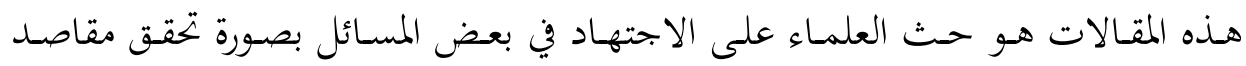

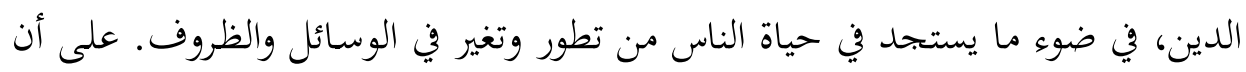

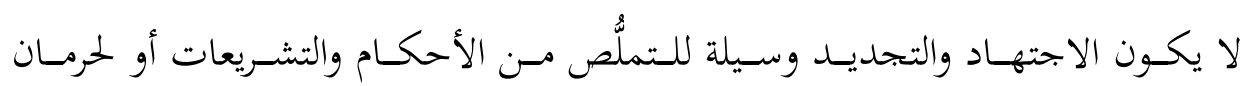
المسلمين الحكمة المنشودة منها.

ونستأنف في هـا المقال استفتاء الأمة في مسألتين تختص الأولى بمواقيت الصلاة،

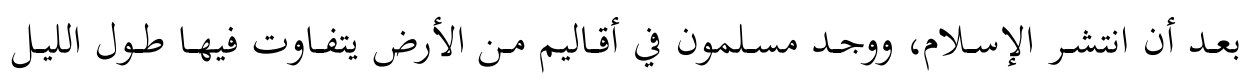

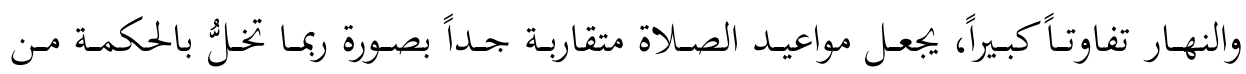
توزيعها على ساعات اليوم؛ ليله وهاره.

أما المسألة الثانية فهي تختص بصوم رمضان وتفاوت ساعات الصيام في النهار من

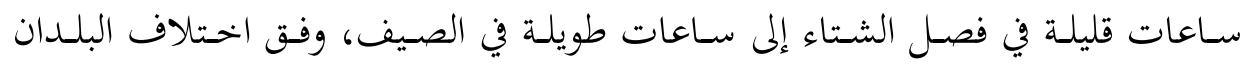

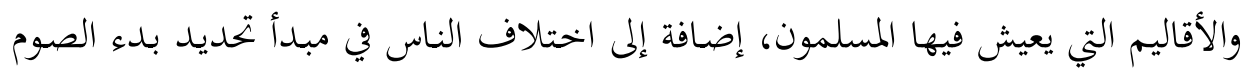

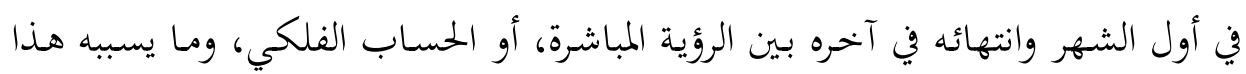
الاختلاف من فرقة وتنازع.

* دكتوراه في العلاقات الدولية، مدير الجامعة الإسلامية العالمية في ماليزيا سابقاً، ورئيس بحلس أمناء المعهد العلمي

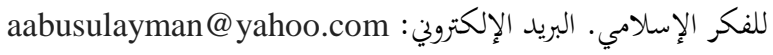




\section{أولاً: مواقيت الصلاة}

من المعلوم أن ثلاثة من أركان الإسلام قد فصّلها القرآن الكريم، وهذه الأركان هي:

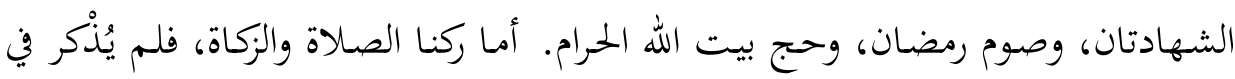

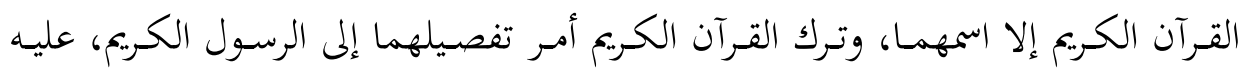
أفضل الصلاة والسلام.

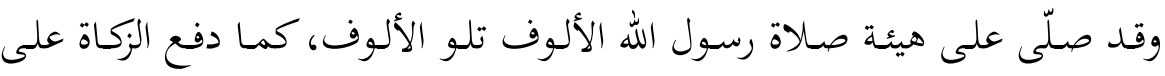

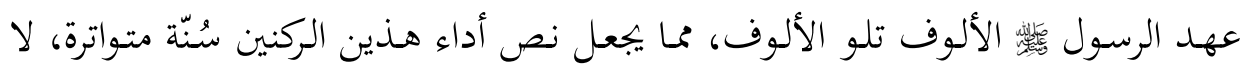

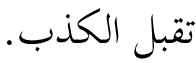

ولكي نتبين هذا الأمر المهم، من الضروري أن نقرأ القرآن الكريم قراءة دقيقة واعية،

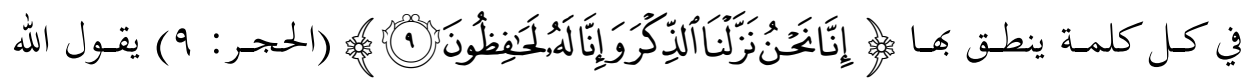

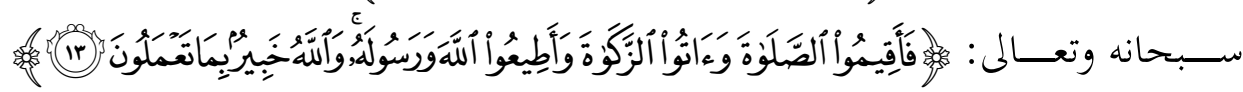

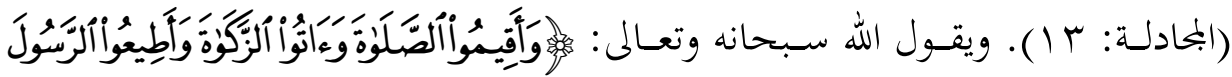

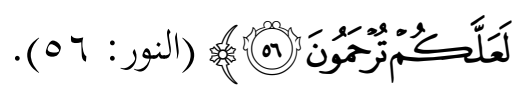

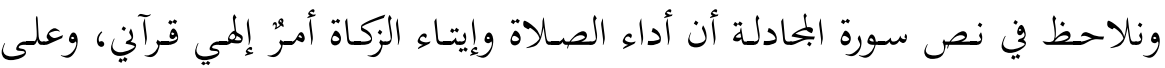

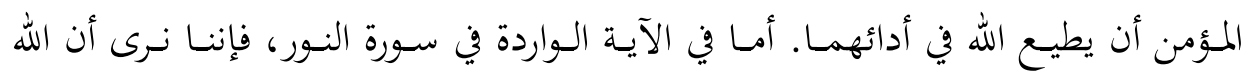

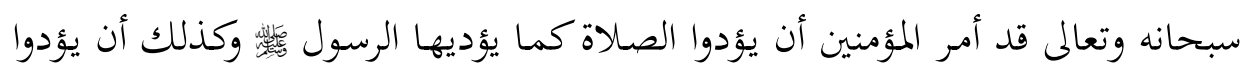
الزكاة كما يؤديها الرسول فئسل، ويأمر المؤمنين بأدائها.

وهكذا نرى أن الله أوحى بإقامة الصلاة وإيتاء الزكاة، وأمر المؤمنين أن يؤدوهما كما يؤديهما ويأمر بكما رسوله الكريم. ولهذا كانت صفة الصلاة والزكاة هي على صفة ما ما أدّاه

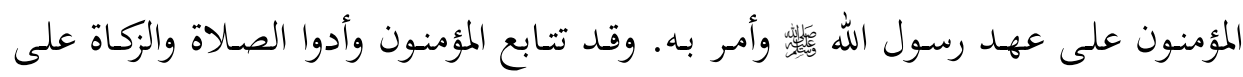

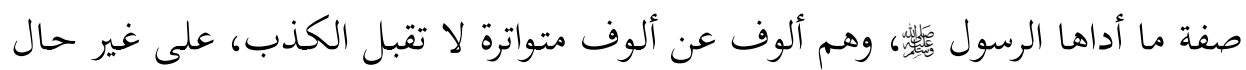
أحاديث الآحاد التي تحتمل الخطأ أو الكذب. 


\section{1. الصلاة توحيد لا تفريق:}

وهكذا فإن الله سبحانه وتعالى، أمر المؤمنين أن يؤدوا الصلاة، وفق أداء الرسول فئس

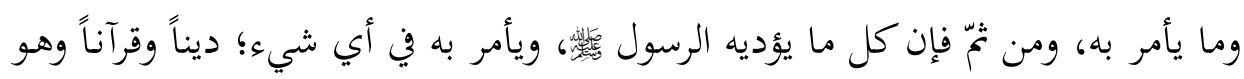

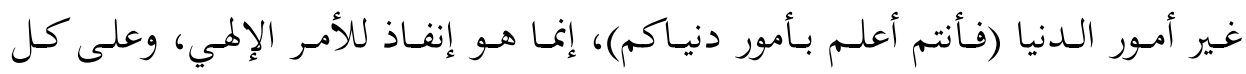
المسلمين طاعته وإنفاذه.

وعلى الرغم من كل ذلك فإننا بحد الأمة، قد انقسمت في أداء الصلاة إلى مذاهب.

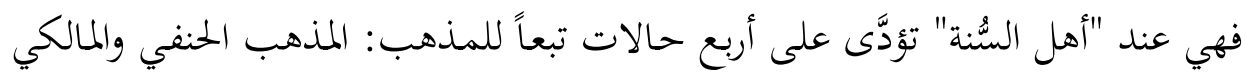

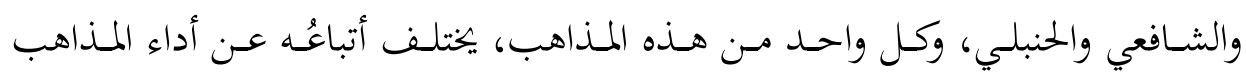
الأخرى، في العديد من أوجه أداء الصلاة.

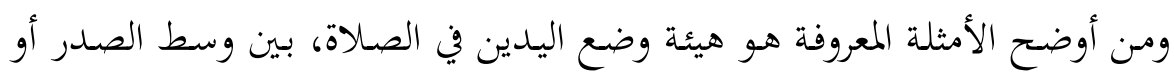

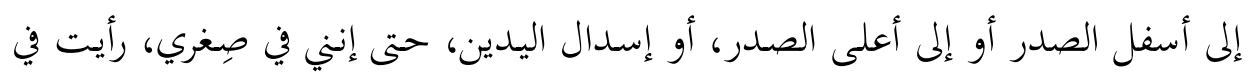

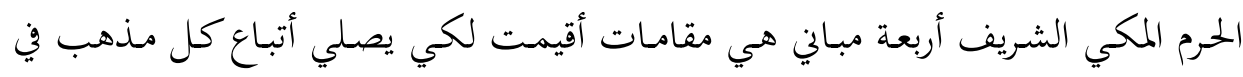

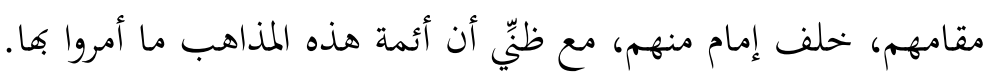
ونحن نعلم علم اليقين، أن هذه السُّنة المتواترة بأمر إلهي، لا يمكن أن يلحق بها خطأ

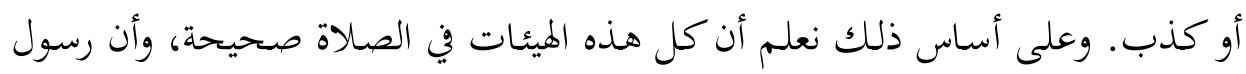

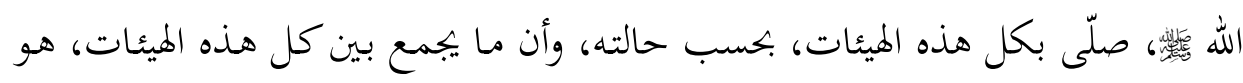
الوقوف أمام الله في الصلاة بأدب.

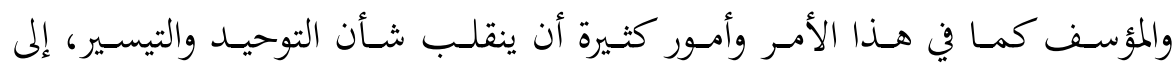

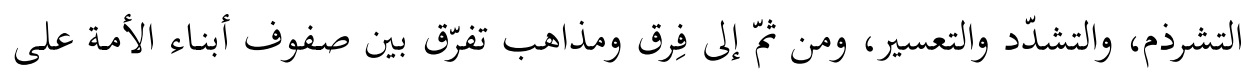
ما نرى اليوم من حالها.

ولماكانت الصلاة تؤدّى كلَّ يوم خمس مرات، فمن المهم جـاً أن ندرك الغايات

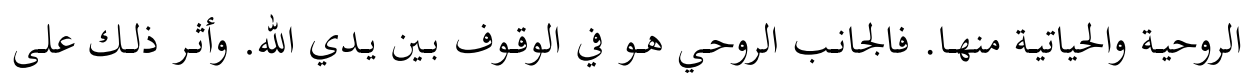

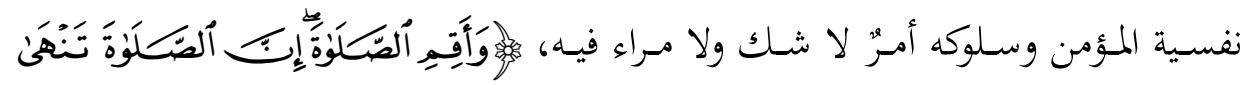




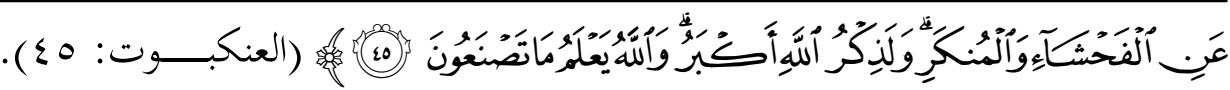

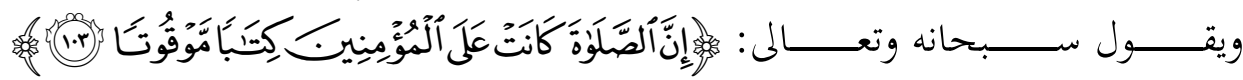

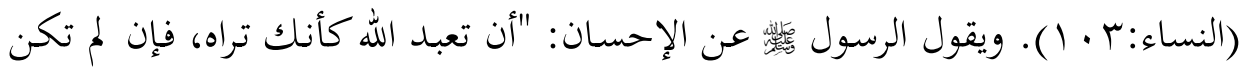
تراه فإنه يراك.

وإلى جانب البُعـد الروحي، فإنان هنـاك أيضـاً الجانب الحياتي، الذي يجبـ أن نـرك

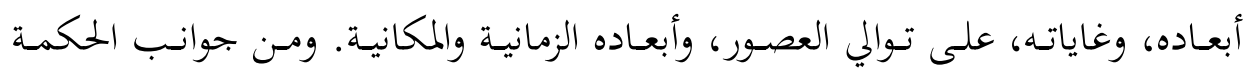

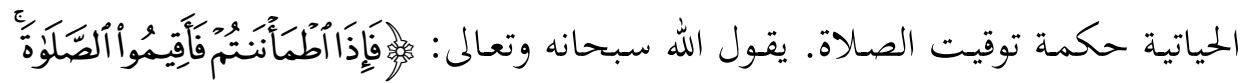

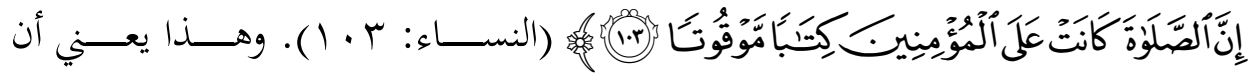

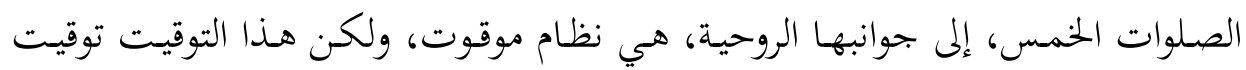

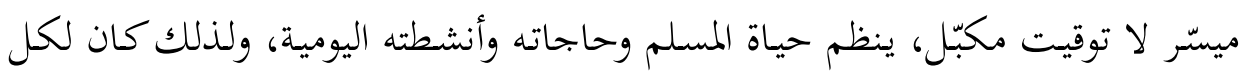
صلاة فسحة من الوقت، ما بين أول وقت كل صالاة وهاية وقتها، وللمسلم أن يؤديها كما يناسب حاله ما بين أول وقتها وآخره، مع العلم أن أول الوقت أفضل مـن تأخيرها من غير سبب.

ومن تلك الحِكمى أيضاً حِكمة الحَمْع، والتي تعني أن يتاح للمسلم إمكانية الحصول على نصـف يوم متّصـل (حـوالي اثنتي عشـة سـاعة)، دون صـالة، لظـروف معينـة، قـــ

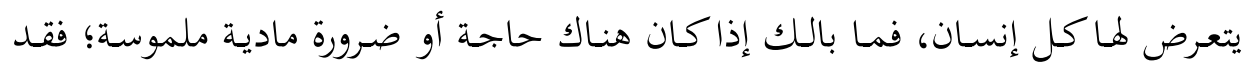

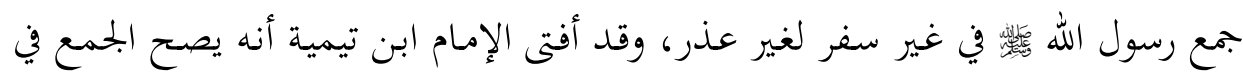
غير سفر لغير عذر على ألا يكون عادة.

وهنا أيضاً تبرز حكمة الجمع وشروطه، فإذا أراد الإنسان أن يجصل على نصف يوم (حوالي اثنتي عشرة ساعة) دون صلاة في وضح النهار، فإنه يجمع صاة الظهر وصلاة العصر ليؤديها قرب وقت هاية صلاة العصر؛ أي قبيل حلول وقت صلاة المغرب، وبهذا يمتد الوقت دون صلاة من صالة الفجر حتى قبيل موعد صلاة المغرب. وإن شـاء المـرء أن يجصـل على نصـف اليـوم في وقـت المسـاء (حسوالي اثنتي عشـرة سـاعة)، دون صلاة، فإنه يجمع وقت العصر إلى وقت الظهر، في أول وقت الظهر، تئ 


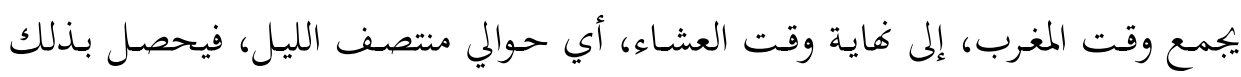

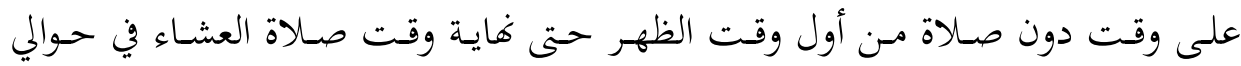
منتصف الليل؛ أي من أول وقت الظهر حنى منتصف اوفت الليل.

وهكذا لو أننا أمعنا النظر في نصوص الدين بندها كلها كما نعلم يُسر لا عسر

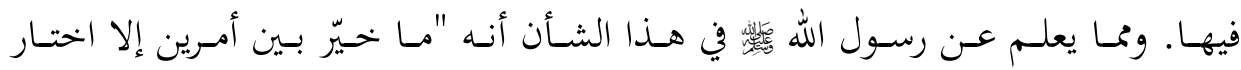

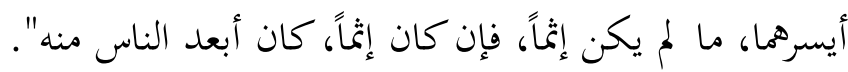

وإذا أمعنا في توقيت جميع أوقات الصلوات، لوجددناها توزع أوقات اليوم إلى حوالي

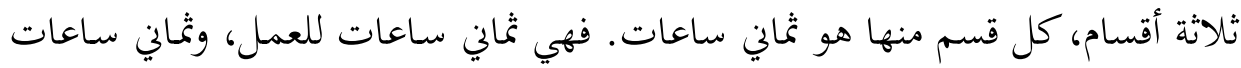

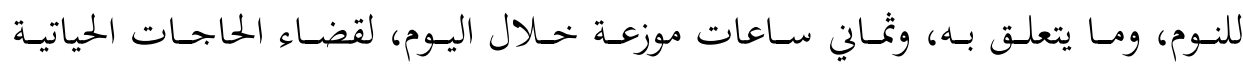

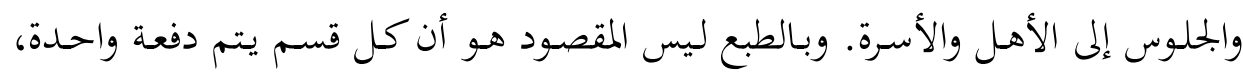

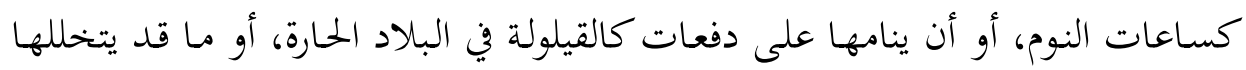

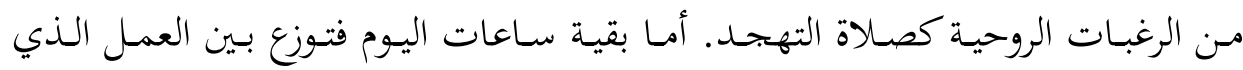

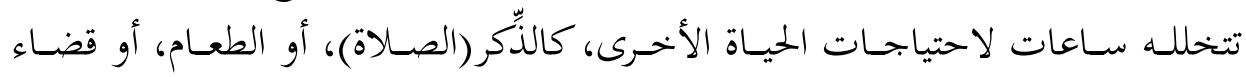

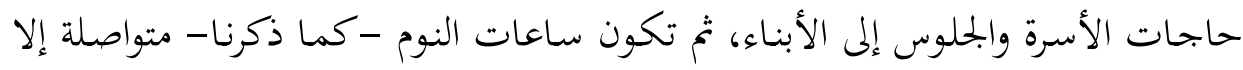
ما شاء الإنسان من الوقت يقضيه في الحاجات الروحية أو الحياتية.

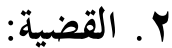

إن كل ما سبق، إنما هو تمهيد وتنوير ضروريان، لعرض القضية المقصودة من هذه

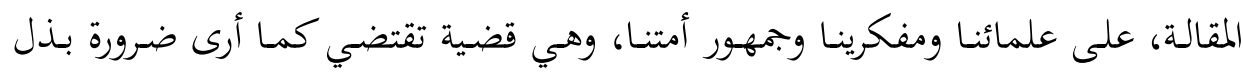

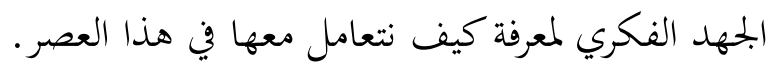

وهذه القضية هي قضية أوقات الصلاة اليومية في الأربع والعشرين ساعة، التي تمثل

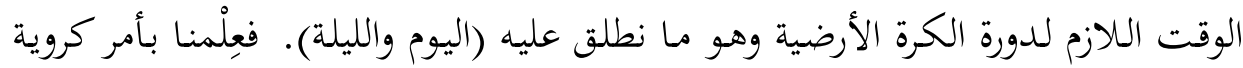

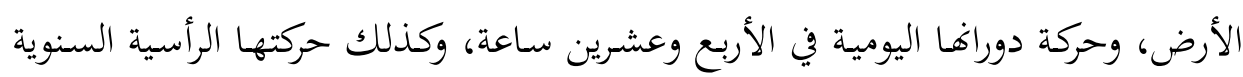

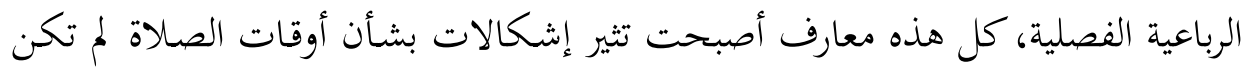
معهودة من قبل. وهذه الإشكالات تستدعي التجديد في التطبيق والاجتهاد فيها. 


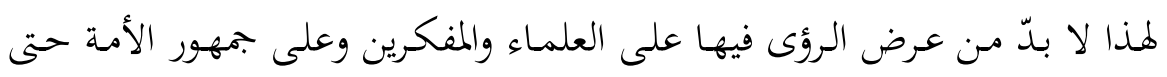

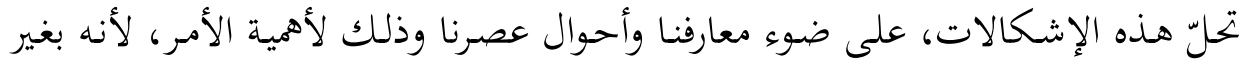
ذلك لا يمكن الجزم بأي نظر علمي أو بصحة أي اجتهاد أو بحديد.

وتفصيل القضية التي نحن بصددها، إنما يـدور حسول توقيـت الصلوات، بمـا يهقق

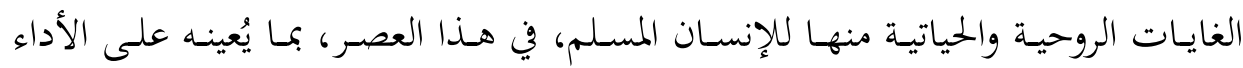
الأمثل لحياته، وتحقيق غايات توقيت الصلوات الروحية والمادية.

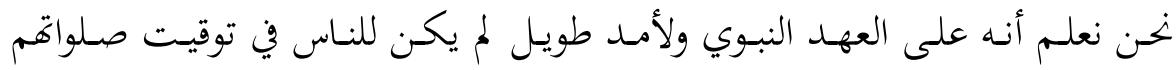

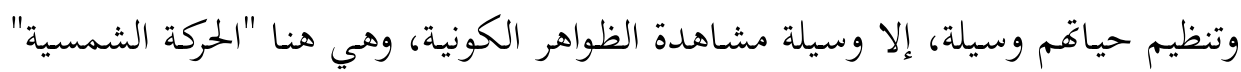

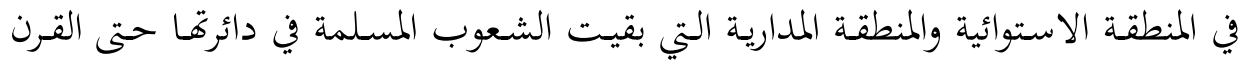

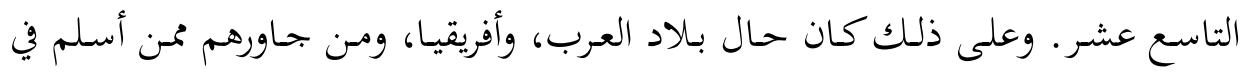

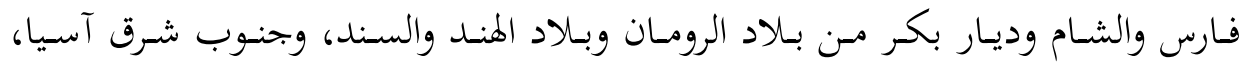

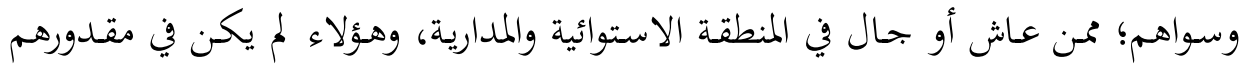

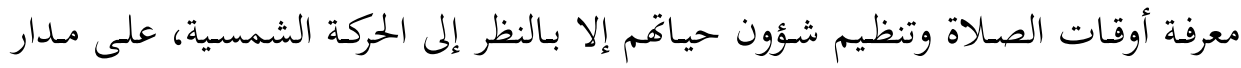
الأربع والعشرين ساعة (الليل والنهار)، التي تكتمل فيها دورة الكرة الأرضية. فالإنسان في ذلك الوقت وإلى وقت ليس بالبعيد كان وهو في قاعة سكنه المبنية من

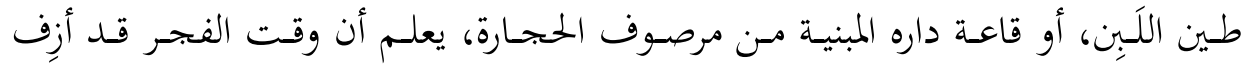

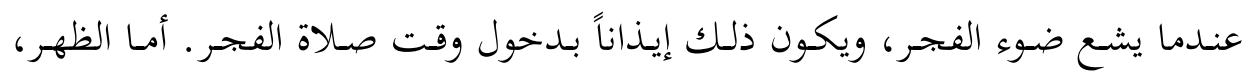

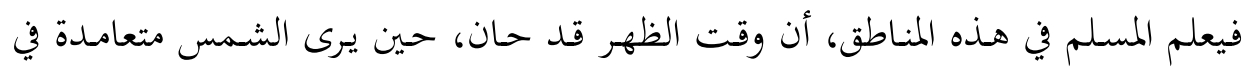

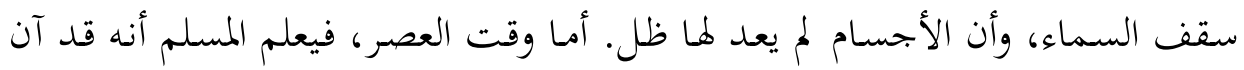

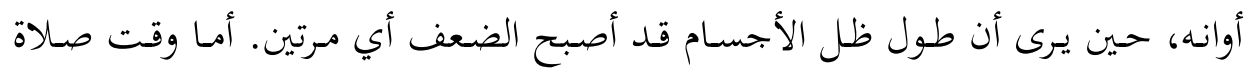

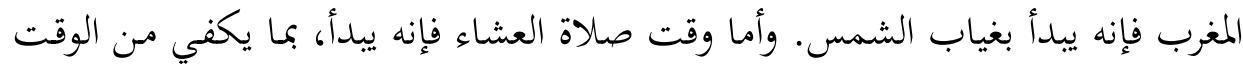

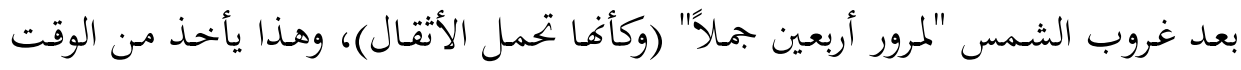

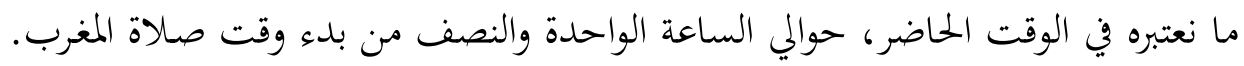

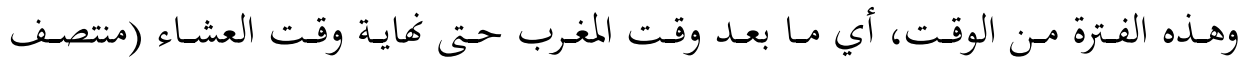

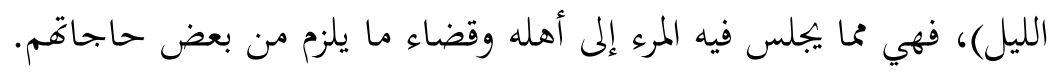


وينبغي لنـا أن ندرك الظروف والإمكانات الزمانية المكانية، للعصر الذي نحن فيه،

منذ بداية القرن الثالث عشر الهجري، (القرن التاسع عشر الميلادي)، وهو الوقت الذي بدأ فيه تطور كبير ملموس في بحال وسائل الصناعات، وفي تطور وسائل النقل والانتقال،

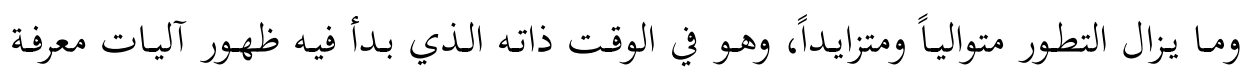

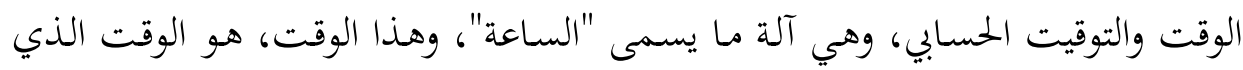
بـدأ فيه امتـاد وجـود المسـمين إلى المنطقة القارية ومـا وراءهـا، مـن المنـاطق حتى المناطق القطبية.

وهنـا لم يعـــ مـن الممكـن اعتمـاد الظـاهرة الشمسـية، في كثـير مـن هـــه المنـاطق الشاسعة على الكرة الأرضية، لتكون أداة لتنظيم الوقت، ولمعرفة أوقات الصلوات في هذه المناطق القارية والقطبية، كما تؤدّى في المناطق الاستوائية والمدارية.

\section{ب. من المدارية إلى القطبية: - من}

كلنـا يعلم أن الإسـلام امتـدّ مـن الجزيـرة العربيـة إلى البلدان الأخهرى إلى بـاد شمـال وشـق وغـرب أفريقيا وعلى سواحل البحر الأبيض والمحيط الأطلسي وإلى بـاد الشـام وبـاد فارس وبـادد السند، وما جاورهما مـن بـاد جنوب شرق ووسط آسيا. واللافت للنظر أن الإسالام بقي في المنطقة الاستوائية والمنطقة المدارية التي تلي المنطقة الاستوائية، إلى القرن الحادي عشر الهجري (القرن الثامن عشر الميلادي).

ومن المعلوم أن منطقة خط الاستواء (المنطقة الاستوائية) يتقارب فيها الليل والنهار. أمـا المنطقة المدارية التي يقع فيها الحَرَمان الشريفان بمكة والمدينة المنورة، فإن طول الليل والنهار يتفاوتـان في فصسلي الصسيف والشـتاء، ولو بشـيء مـن المعانـاة بشـكل ملحسوظ محتمل. أمـا في فصلي الربيع والخريف فيكـون التفـاوت في طول الليل والنهار، أقل مـن تفـاوت الليل والنهار في فصل الشتاء والصيف. وعلى أي حـال فبإن تفاوت طول الليل والنهار مع حرارة الصيف، وقرّ الشتاء، في المناطق الصحراوية يتضمن شيئاً من المعاناة. 
وكما ذكرنا سابقاً فإن المسلمين حين كانوا فيما بين المنطقة الاستوائية والمدارية، في

ظروف ذلك الوقت، لم يكن أمامهم من بدّ إلا أن يعتمدوا الظاهرة الشمسية، لتحديد أوقات الصلوات، كما أن فروقات طول الليل والنهار في هذه المناطق تظل محتملة.

ومن المعلوم - كما سبق ذكره- أنه في تلك القرون السالفة لم تكن هناك من وسيلة أخرى تنظم أوقات صلوات الناس إلا الظواهر الشمسية؛ فجراً، وظهراً، وعصراً، ومغرباً،

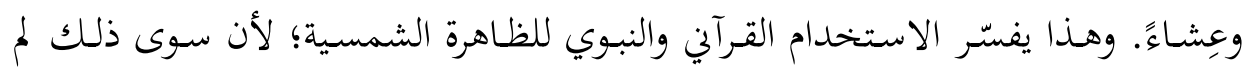
يكن من الممكن تصوّره، والتعامل وَفْقَه في ذلك الوقت

أما في هذا العصر فإن الظاهرة الشمسية لمُ يَعُد من الممكن اعتمادها بعد أن امتدّ الوجود الإسلامي إلى المناطق القارية والقطبية، حيث المناطق الجغرافية والمناخية المتطرفة، في المنـاخ، وفي تفــاوت طـول النهـار والليـل (النـور والظلمـة) مثـل بـاد السـويد وفنلنــدا والنرويج وهولندا وآيسلندا وروسيا وسيبريا وانتهاءً بالقطب، الذي يصل فيه ضوء الشمس في الصيف ستة أشهر متواصلة، ويخيم عليه في الشتاء الظلام ستة أشهر متواصلة. ومع هـذه التطورات، تطورت أيضـاً في هـذا العصر الصسناعات ووسـائل المواصـلات

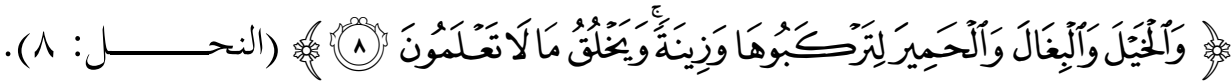

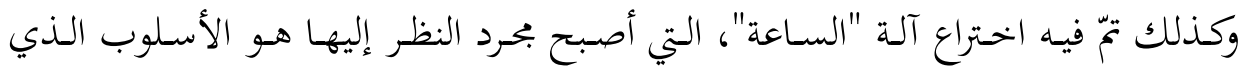
يعتمده الناس جميعاً لمعرفة الأوقات وتنظيمها، بما في ذلك أوقات الصاة في في أي موقع في الصني

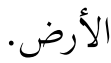

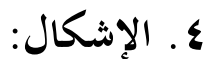

إن الإشكال الذي تدور حوله هذه المقالة، هو أن المسلمين في كثير من هذه البلاد

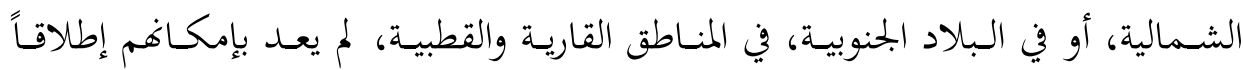
اعتماد الشمس منظمّاً لأوقات الصلوات، وسواها من الأوقات؛ لأن كثيراً من هذه البلاد

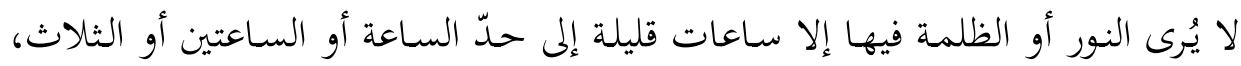
وتكون حالة الظلام عشرين ساعة أو أكثر. بل إن من يصل إلى أقصى القطب الشمالي 


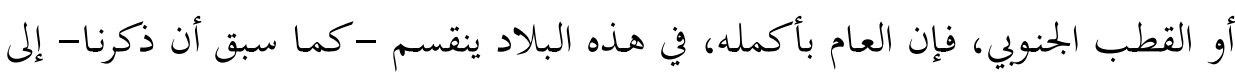

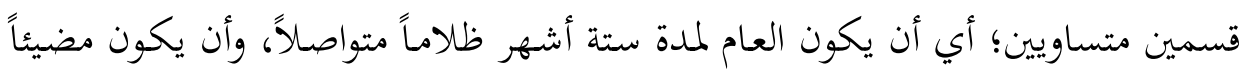

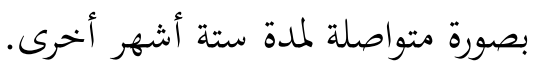

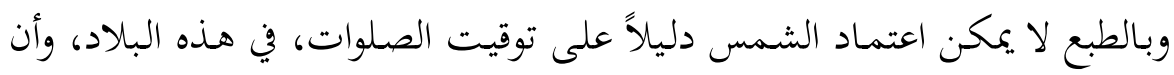

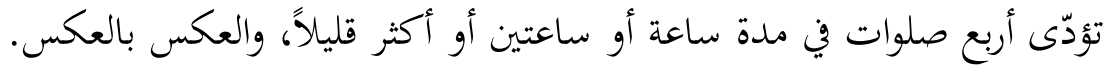

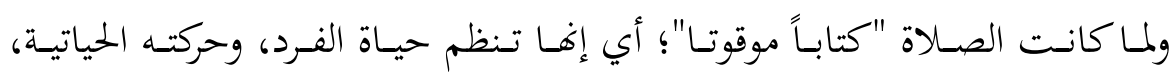

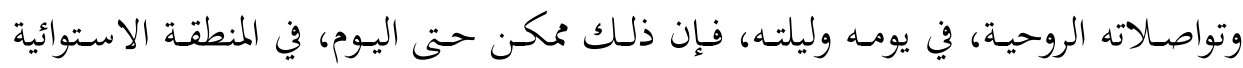

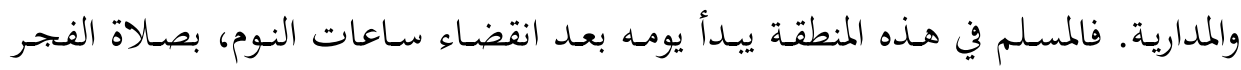

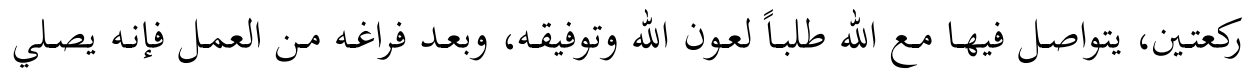

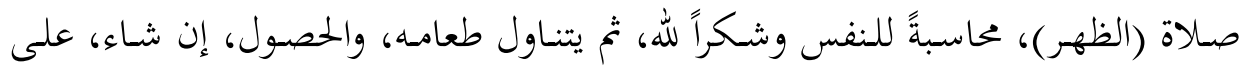

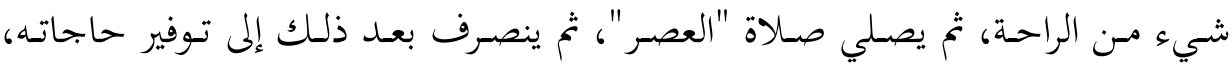

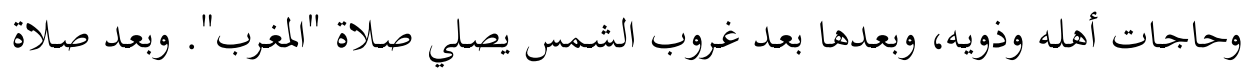

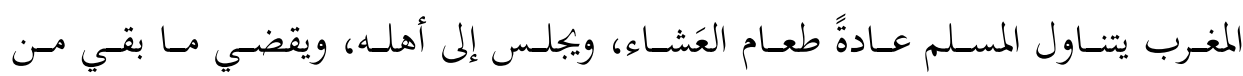

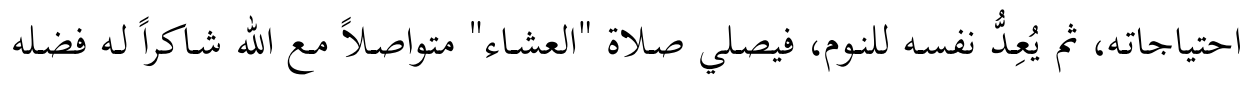
ونعمه.

والإشـكال هنـا هـو، كيف سيتصـرف الإنسـان المسـلم في البلاد القاريـة وفي بقيـة

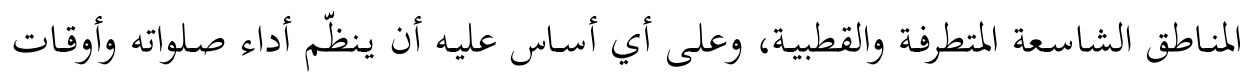
مزاولة شؤون حياته؟

بالطبع نحن نعلم اليوم في هذا العصر، أنه لا يمكن اعتماد حركة الظاهرة الشمسية

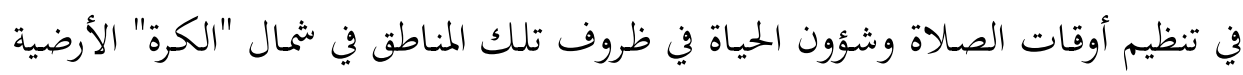
أو جنوبكا.

لقـد أفتى العلمـاء، جزاهم الله خحيراً، واجتهدوا، و "جـددوا"، في أن ينظر المسـلمون

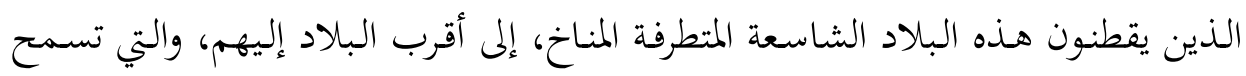


بوضع معقول محتمل، لتنظيم أوقات الصحلاة وشؤون الحياة. ولكن رغـم هذا الاجتهاد، فإن الإشكالية تظل عملياً قائمة، خاصة في بعض هذه البلاد المأهولة بالجاليات المسلمة الكبيرة، مثل بريطانيا، التي يطول فيها اليوم في الصيف إلى حوالي ثماني عشرة ساعة والليل

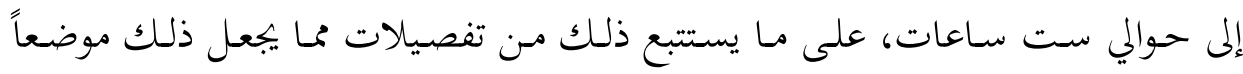

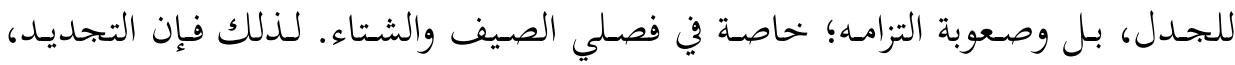
الذي يسمح بتعدد الآراء، واختـلاف تفاصيل الفتـاوى، قـد لا يمثل حقيقـة حـالً جـذرياً

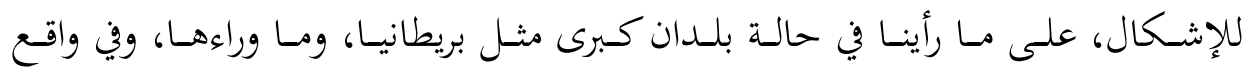
ممارسات كثير من أبناء هذه الجحاليات من المسلمين.

على أية حال، فإن العلماء في فتاواهم قد فتحوا باباً للتيسير، حين أفتوا بأن تنظيم

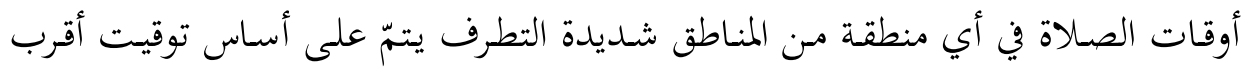

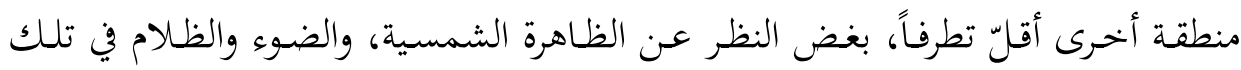
المنطقة. وهذا يعني أن المسلم في مثل هذه البلاد قد يصوم أو يفطر في ضوء الشمس أو أو

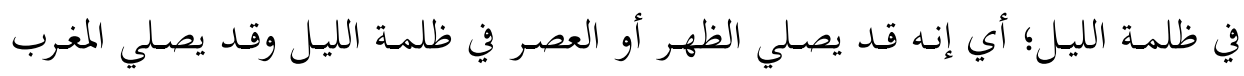
والعشاء في ضوء النهار.

\section{• (الحل الأمثل: تساوي الليل والنهار:}

ما أود طرحه والاستنارة بشأنه بعِلْم علمائنا ومفكرينا ماثله في الآتي: هل من الممكن تحديد أوقات الصيام وتوقيت الصلوات، على حلّ أيسر محا أفتى به

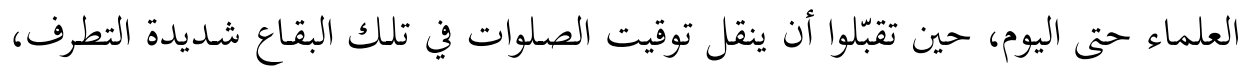

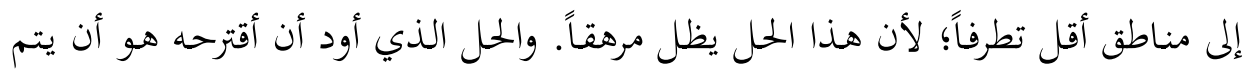

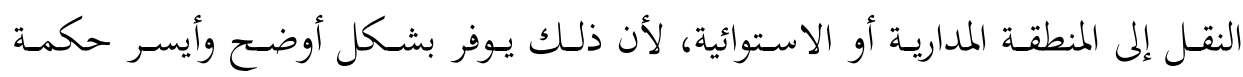
توقيت الليل والنهار لتنظيم أوقات الصلوات وتنظيم شؤون الحياة للإنسان المسلم، في أي لئ بقعة من بقاع الأرض. ليس ذلك فقط، بل إن ذلك، فيما أرى، يجسّد وحدة المسلمين،

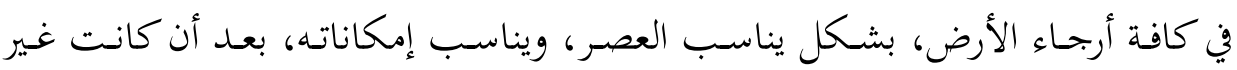
مككنة ولا متصوّرة في العصور السالفة. 
إن الناس، يعلمون اليوم، بمـا يحداث في العالم، في وقت حدوثه، ويتواصلون في التّوّ واللحظة، مع من يرغبون التواصل معه في أنحاء الأرض، بشأن أي توافق أو تخالف. هذا أرى متسائلاً ومستفتياً بشأن "توقيت الصلوات"، وتنظيم شؤون حياة الإنسان المسلم في الأربع والعشرين ساعة على أحد وجهين:

الوجسه الأول: أن يؤخذ توقيت مكة المكرمة، على أساس توقيت جلّ أيامها، وهما توقيت أيام فصل الربيع والخريف، الذي فيهما يتقارب طول الليل والنهار، ويكون هذا التوقيـت للصـلوات، في كل مكـان على وجـه الأرض، وعلى منوالهـا، ممـا يحقـق إمكانيـة تحقيق حكمتها، بشكل أيسر وأوضح. فيكون توقيت الفجر في مكة، هو توقيته في جميع بالاد العالم، وكذلك توقيت وقت الظهر وبقية أوقات الصلوات الخمس هو توقيت الصلوات حسب توقيت مكة المكرمة في جميع أرجاء الأرض، مهما كان الموقع في الأرض؛ شثالاً أو جنوباً، حتى المناطق القطبية، وبغض النظر، إن كان هنـاك ضـوء (شمسى) أو ظلام، مـا دمنـا، بالضـرورة، غير ملتزمين بالظاهرة الشمسية محدداً لأوقات الصلوات، وما دمنا بحكم الواقع، قد قبلنا مبدأ توقيت الصلوات في موقع، على توقيت موقع آخر.

إن المهم في هذا التصوّر، أن توقيت الصلوات، أصبح موحّداً للأمة، ومتوازناً بشكل مناسـب ومحتمل، وأنه يؤدي غرضـه في تنظيم وقـت المسـلم وتوقيـت أوقات الصسلوات؛ روحياً وحياتياً.

الوجهه الثاني: إذا رأى علماؤنا ومفكرونـا، إمكان تحوّل أوقات الصالاة مـن منطقة إلى أخهرى، وأنـه لا يمكـن -بالضـرورة- اعتمـاد رؤيسة حركـة الشـمس لتحديــ أوقـات الصسلوات للمسـلم وتنظيم شؤونه الحياتيـة. وإذا رأى علماؤنـا ومفكرونـا، إمكان اعتمـاد توقيـت مكـة المكرمـة، موحِـداً لأوقـات الصـلوات، وتنظيم حيـاة المسـلم، في جميـع بـاد

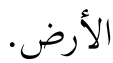


والسؤال هنا: لماذا لا يعتمد خط الاستواء في هذا العصر بظروفه وإمكاناته الزمانية

والمكانية لتنظيم أوقات الصلوات وتنظيم شؤون حياة المسلم، حيث يتساوى الليل والنهار في الفصـول الأربعـة، وهـو توقيـت يسـاوي أيضـاً بـين بـلاد شنـال خـط الاسـتواء، وبـاد

$$
\text { جنوب خط الاستواء؟ }
$$

وهذا الحل أيضاً، يعمّق روح الوحدة بين أبناء الأمة، ويساوي بين جميع أبنائها، وبين جميع مناطقها اليوم كماكان بالأمس إلى حدّ بعيد، وتظل الصـلاة كتاباً موقوتا، تنظم حياة الفرد بالشكل الذي ربما كان هو الحل الأمثل لتحقيق الغاية منها، في هذا العصر. وممـا يؤيد هـا الحـلّ، هـو أن الفرد إذاكـان في منطقة متطرفة شنمالاً أو جنوباً، فِإن عليه إذا ما انتقل هذا الفرد نفسه، بالطائرة إلى منطقة مكة المكرمة أو أي بلد من بـاد المنطقة الاستوائية أو سواها، عليه أن يجعل توقيت صلواته، على توقيت البلد الذي انتقل إليه، والمخالف لتوقيت بلده الذي جاء منه.

وهنا يظهر سؤال مهم: لماذا يُلزم هذا الفرد، بتوقيت الصلوات في البلد الذي انتقل إليه، زيادة أو نقصاً، وليس له أن يبقى على توقيت بلده الذي جاء منه؟! إن عــدم الأخهـ بمفهـوم توقيـت خـــ الاسـتواء، لا يمثـل إلا التمسـك بالظــاهرة

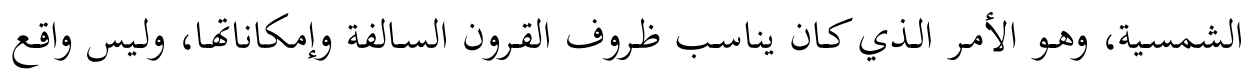
هذا العصر وعلومه وامكاناته وضروراته. ومن المهم هنا أن نشير إلى أن الصلاة على توقيت خط الاستواء لا ينال من مكانة المسـد الحـرام، لأنه يظل قبلة المسـمين في أي موقع كانوا في أرجاء الأرض، يتوجهون إليه ويعظمونه.

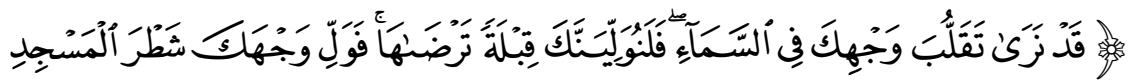

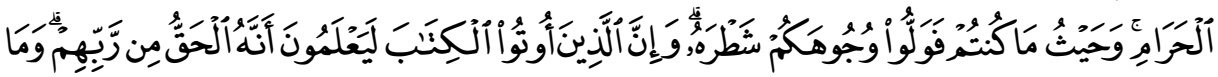

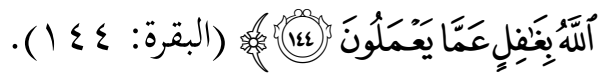


وإذا كانت الكعبة المشرفة والمسجد الحرام بمكة المكرمة قِبلة الصالاة لجميع المسلمين في جميع أرجاء الأرض، توحّدهم أياً كان موضعهم على وجـه الأرض؛ قُرباً وبُعداً، شرقاً

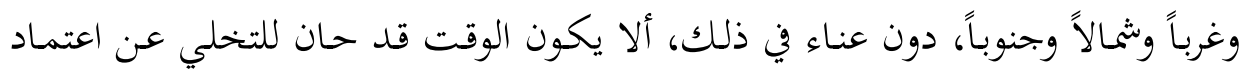
الظاهرة الشمسية وسيلة لتحديد مواقيت الصالاة والصيام، في جل أنحاء الكرة الأرضية، واعتمـاد خط الاستواء في منتصف الكرة الأرضية لتحديـد هـذه المواقيـت؟ فيكـون هـذا التحديـد موحـداً للأمـة في صـلاتما وصـيامها، كمـا يوحّدهم المسـجد الحـرام قبلة توحيـد ووحدة وهداية وعدل واعتدال لجميع المسلمين، لا فُرقة ولا حيرة ولا اختلاف ولا تمزق وتناحر، يدبره ويسعد به العدو وتشقى به الإنسانية وشعوب الأمة؟

إن مسن المطلوب والمرغوب في واقع العصر أن تطرح على السـاحة الفكرية، وبكل

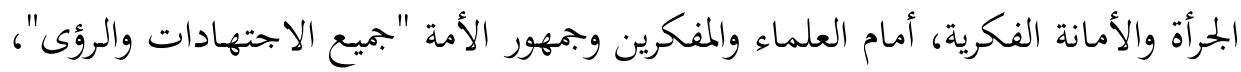
ليتداولوها، ويتدبروها، فأمر الأمة المسلمة "شورى بينهم"، "ولا بتمع الأمة على ضلالة".

ثانياً: صوم رمضان

قضية صوم رمضان من أهم القضايا التي يثيرها ويفرضها الفكر ويستوجب التفكير فيها في هذا العصر، لا سيما في ظل تطورات العصر وتنامى إمكاناته، بما في ذلك اختراع

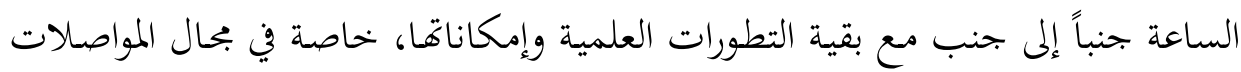
والاتصالات بكل أشكالها؛ مروراً بما أصبح سائداً من أنواع التواصل الإلكتروني؛ صوتاً وصورة، ومع أي إنسان آخر في أي جزء من بلاد الأرض، وانتهاءً بما سوف يستجلُّ مـا

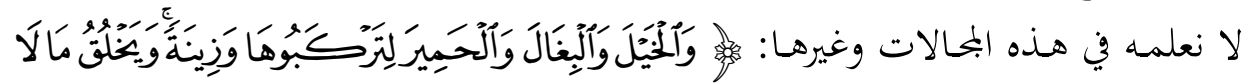

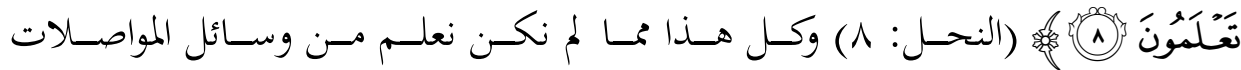

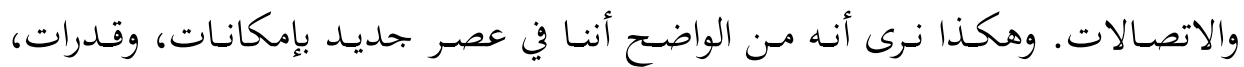
وحاجات عديدة، تؤثر على نوعية الحياة بشكل غير مسبوق.

فــاذذا أضـفنا إلى ذلكـ، امتـداد الإسـلام والوجـود الإسـلامي، إلى مـا وراء المنطقـة

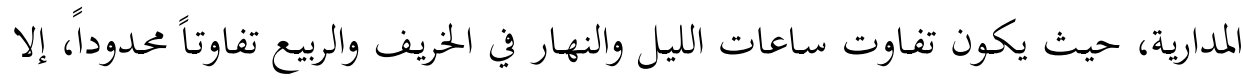


أن تفاوت ساعات الليل والنهار في فصلي الصيف والشتاء، كبير ومرهق بعض الشيء. وهكذا يظل الصيام في فصل الشتاء مقبولاً، أما في فصل الصيف فيكون الصيام صعباً خاصة لمن كان عمله شـاقّا، وقد يصعب تصوّره لو اقتضت الضرورة أن يكون في قيظ الشمس.

ولا أنسى أن أحسد المسؤولين في إحـدى الملحقيات الثقافية في بريطانيا، التي يـدرس فيها مئات الألوف مـن الطلاب الذين جـاءوا مـن العـا لم الإسـلامي، وذلك يستوجب بالطبع عملاً متواصلاً في حل إشكالاتمم، ومتابعة تحصيلهم الدراسي، في جامعات تلك

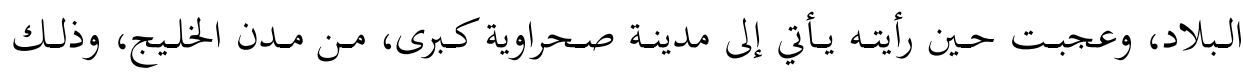
ليصوم رمضان، في داره بها، رغم جوّها الساخن، بل وأحياناً المحرق، الذي يشوي الوجوه تحت أشعة الشمس. وعندما سألته، وكأنني أسأل من فقد عقله، ما الذي أتى بك من "لندن" لتصوم في هذا القيظ اللافح الذي يسجنك في الغرف المكيّفة. أجابني إجابة كانت مفاجأة، حين قال: كيف لا آي وسـاعات اليوم في لندن، هي حوالي "ثماني عشرة سـاعة"، مع عمل جادّ مرهق في خدمة الشباب المنتسب إلى الجامعات، في جميع أنحاء بريطانيا. وبالطبع فإننا نعلم أنه كلما ابتعدت البلاد عن المنطقة الاستوائية التي يتعادل فيها النهار والليل، أياً كان هذا الابتعاد إلى الشمال أو الجنوب، فإن طول الليل والنهار يزداد تفاوتاً؛ طولاً وقصراً، كما أوضحنا من قبل.

وحتى في المنطقة المدارية التي يقع فيها الحرمان الشريفان بمكة والمدينة، فإن تفاوت

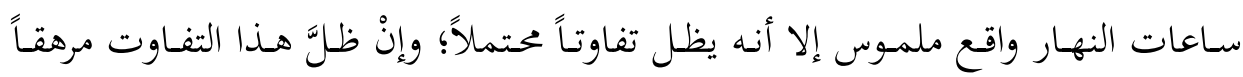
بعض الشيء للعاملين، حين يكون الصوم في الصيف، والعمل تحت الشمس. ولماكـان المسـلمون في المنطقـة المداريـة، في العصـور السـالفة، لا سـبيل لهـم لمعرفـة الأوقات، إلا بالنظر إلى الظاهرة الشمسية؛ فكان تتبع الحركة الشمسية إشراقاً وغروباً، هما 
أداة الإنسان لمعرفة أوقات النهار والليل، كان الصيام عند المسلمين في بلاد هذه المنطقة يبدأ من الفجر وإشراق الشمس حتى غروب الشمس وحلول الظلام والليل.

والقضـية التي أود طرحها مستفتياً أجـاء علمائنسا ومفكرينـا وجمهـور أمتنـا المسـلمة

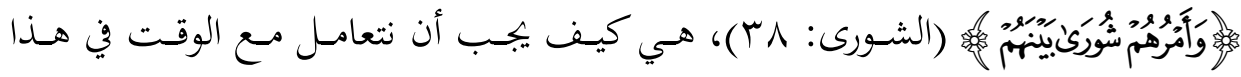
العصر، مع تفاوت ساعات "الليل والنهار"، في بعض المناطق، إلى الحـدّ الذي يصل فيه وقت النهار(ضوء الشمس) في المناطق القارية والقطبية إلى ساعة أو ساعتين في الشتاء، واثنتين وعشرين أو ثلاث وعشرين في الصيف، بل إلى حدّ أن يصل في المنطقة القطبية إلى ستة أشهر ظلاماً متواصلاً، وستة أشهر ضوءاً متواصلاً، كما سبق أن ذكرنا. وكمـا نعلم فإن هنـاك مـن المسـلمين مـن يعسيش في سيبريا مـن بـاد المنطقـة القطبيـة

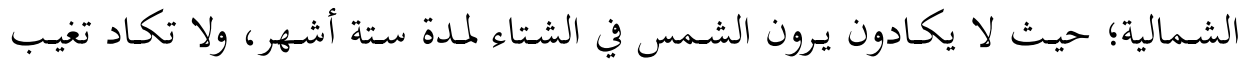
الشـمس في بلادهـم لملدة ستة أشهـر أخـرى. وبـذلك يتعرض المسـلم إلى حسال يستحيل معه، اعتبار الضوء والظلمة، له أية علاقة بتوقيت شعيرتي الصلاة والصوم. ومسن المعلوم لنـا أيضاً أن هناك قبائل بشرية شمـال القـارة الأمريكيـة تعيش حياتها في المنطقة القطبية ومنها قبائل الأسكيمو. وليس هناك ما يمنع بعض أبناء هذه القبائل من الإسـام لو بلغها واهتمّ الدعاة بها، ممن هـم قادرون على ارتياد المناطق شـيدة البرودة وشديدة التطرّف في تفاوت أوقات "الضوء والظلمة"، مما لا يكون فيها للحركة الشمسية أي اعتبار في أداء شعائر الصلاة أو الصيام.

\section{ا ـ تحريك مدة الصيام شمالاً وجنوباً وفق الطاقة البشرية:}

والسؤال هنـا لأجـاء علمائنسا ومفكرينـا وجمهـور أُمّنتـا: كيـف يكـون صسيام هـؤلاء

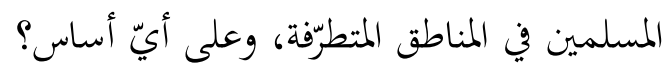
ففي بريطانيا مثلاً، والبلاد التي على شاكلتها يعد المسلمون بالملايين، وعليهم أن يصوموا "النهار" رغم طول ساعاته، خاصة في فصل الصيف. وهذا الوضع في مثل هذه 
البلدان قد يدعو بعض المسلمين محّن رقّ دينهم، وشقّ عملهمم، إلى أن يتركوا الصيام، أو يصومون صوم الصيف قضاءً في فصل الشتاء؛ إذ ضوء الشمس لا يظهر إلا لحوالي ستّ

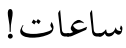

وإذا قبلنا وَفْقَ فتوى المفتين التي لا ينكرها عليهم أحد يمّن لديه دراية علمية بطبيعة الكرة الأرضية بما يتعلق بشأن الصيام، بتجاهل الظاهرة "الشمسية" لهؤلاء المسلمين الذين يعيشـون في البلـدان الشـمالية أو الجنوبيـة المتطرفـة وصسوم رمضـان حسـب توقيـت أقرب منطقة يكون تفـاوت الليل والنهار فيها، أقلّ تطرفاً، مثل بريطانيا، ليكون أداء الصهاة وصوم رمضان أكثر تحقيقاً للحياة الروحية للمسلم.

وعلى ضـوء مـا سـبق، ومـن رؤيسة علميـة لوضـع عالمنــا المعاصـر وطاقاتـه وإمكاناتهـ وحاجاته، التي بتعله عصراً غير العصور السالفة، فإن منهج "بتحيد الدين"، يحتّم تدبّر حال العصر، وكيف يُعاد تطبيق قيم الدين ومفاهيمه ومبادئه على واقع العصر وحاجاته وإمكاناته زماناً ومكاناً؛ ليحقق مقاصد الدين بعِلْمِ واستنارة. ودون العِلـم والمِكمـة، وإدراك معطيـات العصـر، وعلومهه وقدراته واحتياجاته، غـير

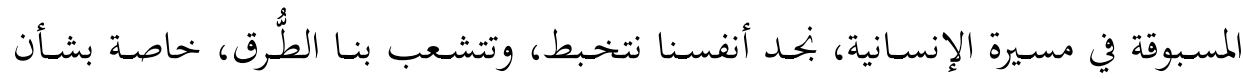
صيام شهر رمضـان، حتى في المنطقـة التي بهـا جـلّ الدول الإسـلامية، بـل وجميع الـدول العربية، كما رأينا سابقاً في موقف أحد حكام منطقة البحر الأبيض المتوسط المدارية؛ إذ يفتى ويأمر العاملين في بلده بالإفطار في رمضان. وليس ذلك فحسب، بل إننا رغم كل ما نعلمه من إمكانات العِلم، وأحوال الأرض، بنحد -حتى اليوم- أن هناك من يحتّم بلدء

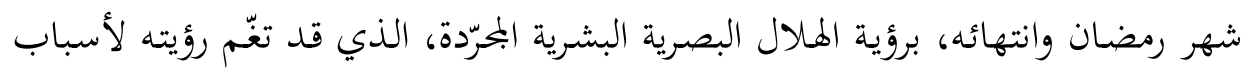
مناخية على البصر الإنساني البحرّد.

وكان هذا النوع من المعرفة مقبولاً في العصور السابقة، بل غدا أمراً حتميّاً لا بدّ منه؛ إذ مثّل عاملاً من عوامل وحلدة بين أبناء الأمة؛ لأن رؤية الهلال في كل منطقة، يعلم بها سكان المنطقة، وهـم سوف يبدوؤن وينهون صيامهم في وقت واحسد وفقـاً لذلك، ولن 


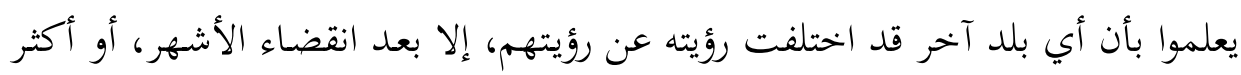
من ذلك، وذلك حين تصل قوافل الركبان على ظهور الإبل بالأخبار.

أمـا اليوم، فثمـة تقدّدمٌ في العلوم والمعارف، وإمكانات التواصل الآني العديدة، التي

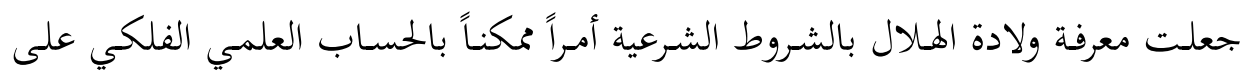
وجه الدقة، بغض النظر عن الظروف المناخية الجحوية المعوّقة لرؤية العين البشرية. وعلى عكس رؤية العين المحردة، التي لا تُعـُُ في أحسن الأحسوال رؤية جميع أبناء

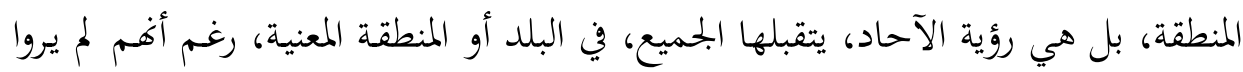
الهلال، فإن دقة حساب حركة الشمس وما حولها من الكواكب، والتي منها القمر، هو

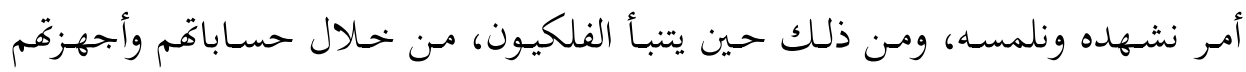

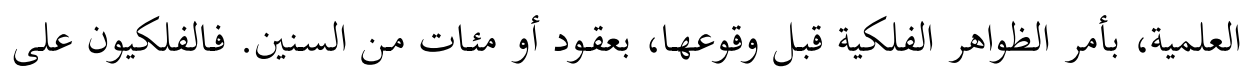

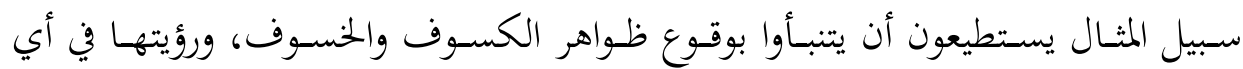
وقت، وفي أي المواقع من الأرض وعلى أية صورة.

والسبب في ضعف الاعتداد بالرؤية البشرية في هـذا العصر، هو أهـا ليست فقط

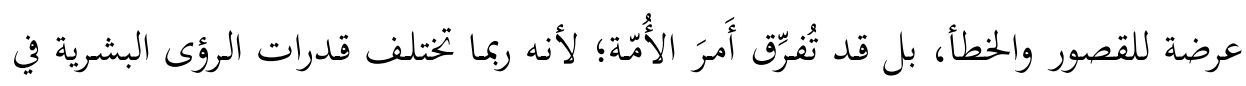
بدء الشهور وانتهائها بما في ذلك رمضان، على غئ غير حسابات علم الفلك التي لا تكاد تقبل الاختلاف. وهنا يقع الخلاف وحسّ الفرقة؛ إذ إن أي قرار في أي بلد بشأن أن الرؤية

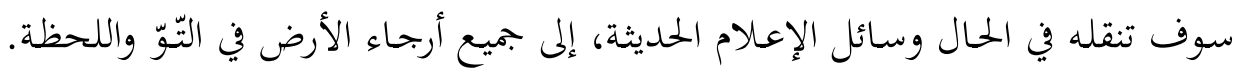

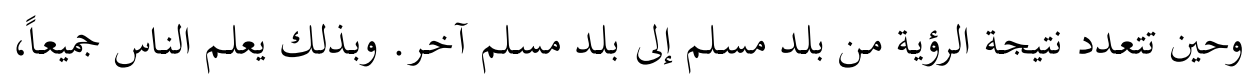

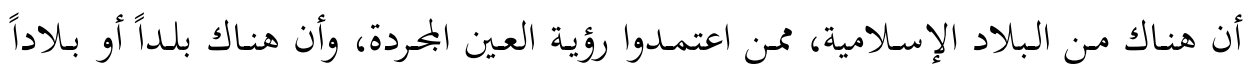

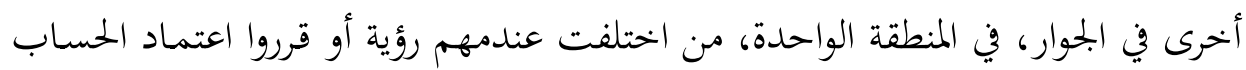

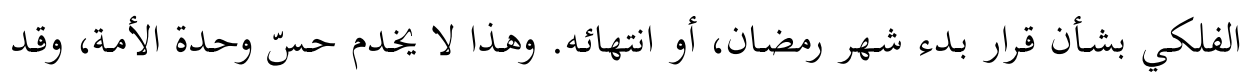
يكون ذلك عنصر فرقة وتنازع. 
والسؤال الآن هو: ألا يمكن في هـا العصر، بحاجاته وإمكانياته، أن نحلّ كلّ هذه

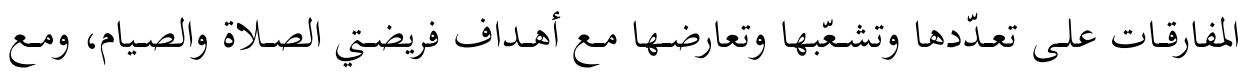
تعميق حسّ وحدة الأمة، وذلك بأن نلجأ إلى العِلم، لكي نحقق مقاصد الشريعة، وقيم الإسلام ومفاهيمه ومبادئه، بما يناسب هذا العصر؟!

هل هذا أولى؟ أو أنه لا بدّ لنا من التقليد، والمتابعة لعصور سالفة، حالها غير حال هذا العصر، وحاجاتا غير حاجاتنا، وإمكاناقا غير إمكاناتنا.

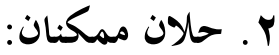

إنّ لـبّ مـا أراه وأسـتفتي فيـه أهـل العِلـم والمعرفـة والفكـر وجمهـور الأمـة هـو : هـل بإمكانـات العِلم (الحسـاب الفلكي) وقـدرات وسـائل الإعـلام في نقـل الأخبـار في التّوّ

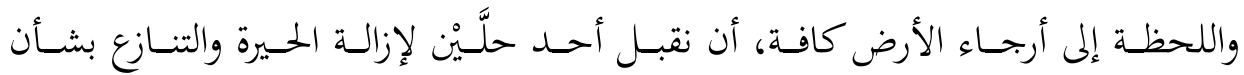
إشكالات أداء فريضة الصيام في هذا العصر؟

الحل الأول: إذا كان علماؤنا الأجحلاء قد أفتوا بنقل توقيت الصيام ومواعيد الصلاة بدءاً وانتهاءً إلى أقرب منطقة، يقدّر الإنسان احتمال طول النهار والليل فيها. أفلا يصبح

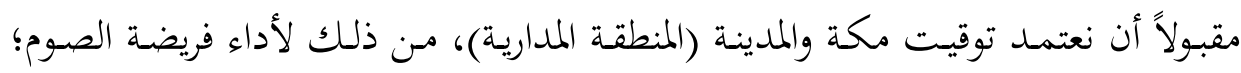

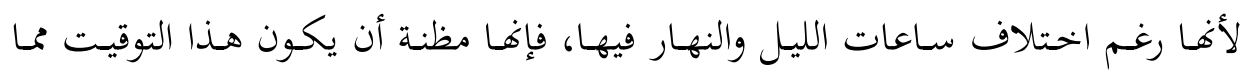
يناسب جميع بلاد المسلمين في العالم. وعلى الرغم من أن في هذا التوقيت بعض المشقة للناس، إلا أنه ما يزال محتملاً.

الحل الثاني: وبذات المبدأ في تجاهل الظاهرة الشمسية، وتريك شأن التوقيت إلى توقيـت أقرب منطقـة، يكون التوقيـت الشمسي محتملاً ولو بشيء مـن المشقة، نعـرض

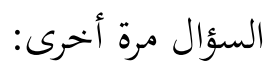

ألا يمكـن اعتماد منطقـة خط الاستواء، الذي يقسّم ساحة الأرض جميعها إلى

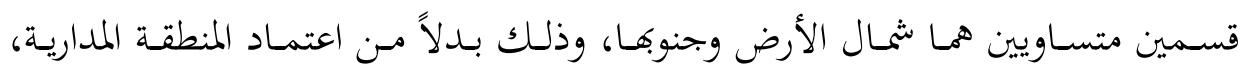


ليكون توقيت المنطقة الاستوائية هو توقيت أداء فريضة الصيام، في جميع أنحاء المعمورة، وبذلك فإننا نسوّي بين المسلمين في جميع أخحاء المعمورة، في صوم ساعات أيام رمضان.

أليس في هـذا الحـل مـا يُمكّن مسن الاسـتفادة مـن الإمكانـات العلميـة، وتـأثير آلـة

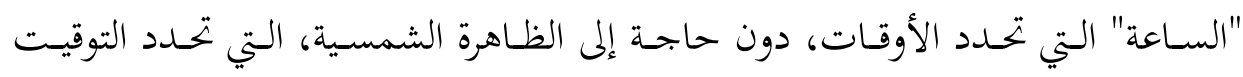
بصورة توقع مشقة على الصائمين؟

ونتيجة اعتماد هذا الحل يتوحّد ويتساوى بـدء صوم اليوم إلى انتهائه، أينما يكون المسلم في أقاليم الأرض، ليكون اثنتي عشرة ساعة. وبناء عليه يحدث مزيد مـن التوحيد والتيسير وتحقيق مقاصـد الصيام بلجميع المسـمين في جميع أرجـاء الأرض شثـالاً وجنوبـاً، مهما تطرّف الموقع. وهكذا فإن من ينتقل من أي موضع في الأرض إلى أي موضع آخر

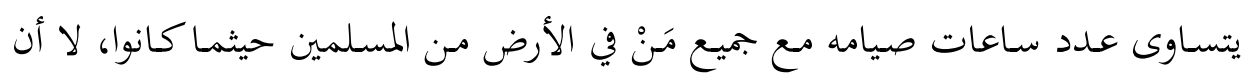
يتفاوت صيام يوم الفرد نفسِه بعد رحلة بالطائرة لعدة ساعات إلى بلد مثل بريطانيا عمّا كـان عليـه، على سـبيل المثنال وهـو في (جاكرتا) أو(كمبـالا) والعكس بـالعكس. فمـا الحلكمـة في ذلك، والشـصص هـو نفس الشـصص إلّا أنّ موقعه مـن الأرض تغيّر ليكـون الأمر للأول في جاكرتا أو كمبالا يُسنراً، ولآخر في بريطانيا مشقة وعسراً؟!

إن هذه الرؤية "الاجتهاديـة"، فيمـا أرى هي محـا يقوّي لُحمة الأمـة، وَحِسَّ وححدهما، ويُيسـر عليهـا أَمـرَ حياتها، وحُسنـن أداء شـعائرها، وتحقيـق غاياتهـا الروحيـة والحياتيـة، ويتناسب مع طبيعة العصر وإمكاناته. وكل هذه الرؤى، والنظرات، والخواطر الاجتهادية، التي خطرت بذهني هي نتيجة التأمل في أحسوال العصر، وحاجاته، وإمكانياته؛ الزمانية والماكانية.

ومـن المهمم أن نـرك أن هـذا الحـلّ، لا يؤثر على مكانـة المسـجد الحـرام وقدسيته، وضروة التوجه في الصالة إليه، من موقع إقامة الصلاة في أي مكان في هذا العالم. 
وحرصاً على بذل الجها، ومشاركة ما ارتأيته من الفكر والرأي، مع أجلاء رجالات

الأمة، من العلماء، والمفكرين، ومع جمهور الأمة الملتزمين المستنيرين، طرحت هذه الرؤية "الاجتهادية" مستفتياً جميع هؤلاء، للنظر في هذه القضية المستجدة المهمة، وسواها من القضايا المماثلة في هذا العصر، بكل الجحّ والجدية؛ فالدين يُسر لا عسر (لا بحتمع أمتي على ضـالة). فليس لي ولا لسواي إلّا مـا يراه أهـل العلم والفكر المستنير ويجتمع عليه جمهور الأمة المستنير. والله الموفق والهادي إلى سواء السبيل. وآخر دعوانا أن الحمد لله رب العالمين 